$\mathbb{T}$ periodica polytechnica

Civil Engineering

57/1 (2013) 3 9

doi: $10.3311 / P P c i .2136$

http://periodicapolytechnica.org/ci

Creative Commons Attribution (i)

RESEARCH ARTICLE

\section{Biomechanical modelling of the accommodation problem of human eye}

Zoltán Bocskai / Imre Bojtár

Received 2012-12-06, accepted 2013-03-05

\begin{abstract}
This paper deals with the biomechanical analyse of the human eye with a complex numerical model. We present our three dimensional finite element model including the built-up parts, applied material and geometric properties. Hereupon we describe the subjects which we want to investigate with this $3 D$ model, such as accommodation, presbyopia and so on. We highlight the accommodation problem of the crystalline lens and its surrounding parts. We discuss and explain the connection between the age-related material properties, geometric and refractive parameters and amplitude of accommodation. The results have shown that beside the geometry and material properties, the refractive attributes might be important too.
\end{abstract}

\section{Keywords}

$3 D$ finite element model $\cdot$ accommodation $\cdot$ age-related parameters $\cdot$ crystalline lens $\cdot$ human eye

\section{Zoltán Bocskai}

Department of Structural Mechanics, Budapest University of Technology and Economics, Múegyetem rkp. 3, H-1111 Budapest, Hungary e-mail: zbocskai@mail.bme.hu

\section{Imre Bojtár}

Department of Structural Mechanics, Budapest University of Technology and Economics, Múegyetem rkp. 3, H-1111 Budapest, Hungary

e-mail: ibojtar@mail.bme.hu

\section{Introduction}

The eye is one of the most important sensory organs of the human body. The human eye is an almost spherical elastic organ with spatial elastic support. The properties of its components are always considerably age-related. There are several studies and numerical investigations which dealt with these subjects: Abolmaali et al. (2007) [1], Burd et al. (2002) [7] and Liu et al. (2006) [16]. The biomechanical model of a human eye consists of two basic systems: cornea-sclera with the ciliary muscle and crystalline lens. Each of the two systems is modelled separately due to their different purposes, but the complex modelling of the human eye is rare, despite of the fact that the surrounding parts can influence the results, such as the elastic bearing with the fatty tissue.

We have built a complex three dimensional finite element model which contains the biologically and mechanically required parts for biomechanical analysis that we want to analyse.

In this paper we do not use all the advantages of the complexity of our model, we only want to show one field that we can analyze with it. But we emphasize that it is unequivocal that if we want to analyze, for instance, the movement of nonsymmetric intraocular lens implantation or effects of blunt eye injuries, the 3D model is already indispensable.

We have examined in this paper the accommodation problem based on the classical Helmholtz theory according to the age-related changes in geometry and materials. We note that there are several controversial other theories for accommodation (Schachar, Coleman, etc.), but based on the doctors' opinion from Semmelweis University, Department of Ophthalmology and other specialists (Burd et al.) [7] we accept the classical Helmholtz theory and we do not wish to go into the possibilities of applying different theories and debates. We describe the essence of Helmholtz theory later.

To understand the problem, we have to discuss very shortly what the accommodation of the human eye is. To answer this question we have to look over the main parts of the eye: these are the sclera, the cornea, the ciliary muscle, the zonular fibres and the crystalline lens with nucleus, cortex and capsule (see Figure 11. 


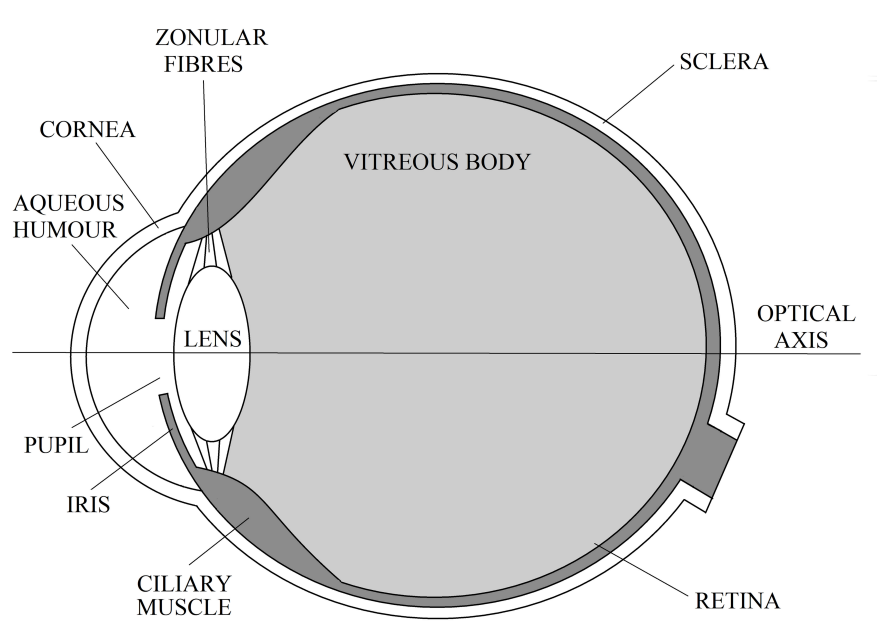

Fig. 1. Section of the human eye

Based on the Helmholtz theory the ciliary muscle contraction causes the lens to thicken and change their shape (Hartridge (1925)) [11], during this process the tension in zonular fibres reduce. It allows us to see objects closely (see Figure 2), this is the accommodation process.

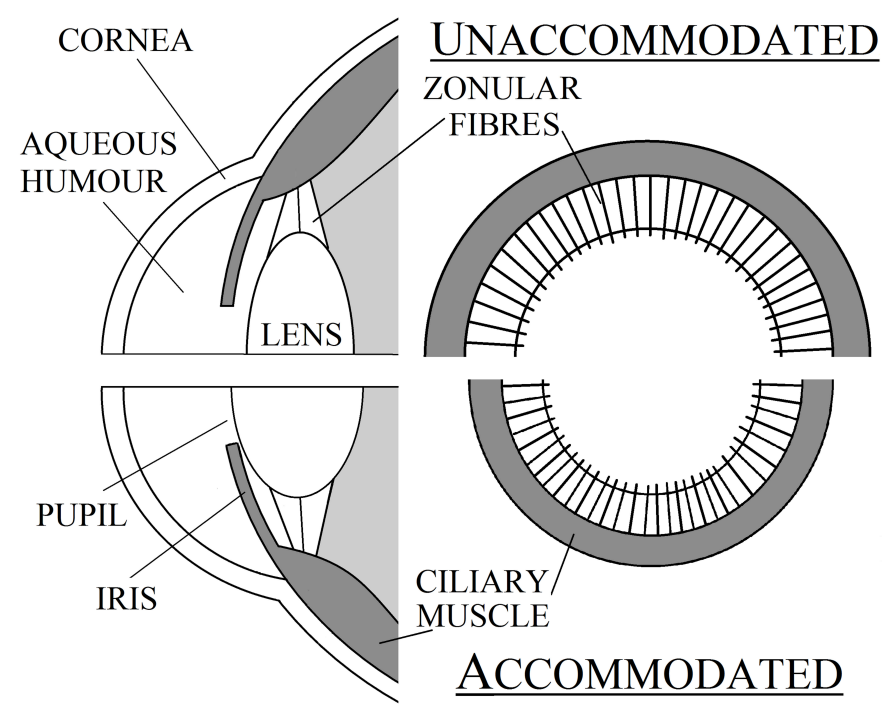

Fig. 2. The accommodation process

When we are young, our crystalline lenses are soft and flexible, so they are able to change their shape easily, allowing focusing on objects both close and far away. Around the age of 40, our crystalline lenses become less flexible (more rigid, with higher Young's modulus) what make it more difficult to see close. We call this phenomenon presbyopia ("aging eye"). The total amplitude of accommodation (accommodation width) is the difference between the lens diopter when we are seeing near and the lens diopter when we are seeing far. The central optical power $(C O P)$ is the diopter of the lens in its optical axis. We can calculate the optical power based on the conventional lens formula (equation (10) to determine the diopter of the crystalline lens.

$$
C O P=\frac{n_{l}-n_{p}}{r_{a}}+\frac{n_{l}-n_{p}}{r_{p}}-\frac{t\left(n_{l}-n_{p}\right)^{2}}{r_{a} r_{p} n_{l}}
$$

where $n_{l}$ - the refractive index of the lens - is assumed to be around 1.44, but it is age-related (see Figure 3); $n_{p}$ - the refractive index of the aqueous humour and the vitreous body - is assumed to be 1.336, Abolmaali et al. (2007) [1], Burd et al. (2002) [7] ; $r_{a}$ and $r_{b}$ are the anterior and posterior radii of curvature; and $t$ is the thickness of the lens.

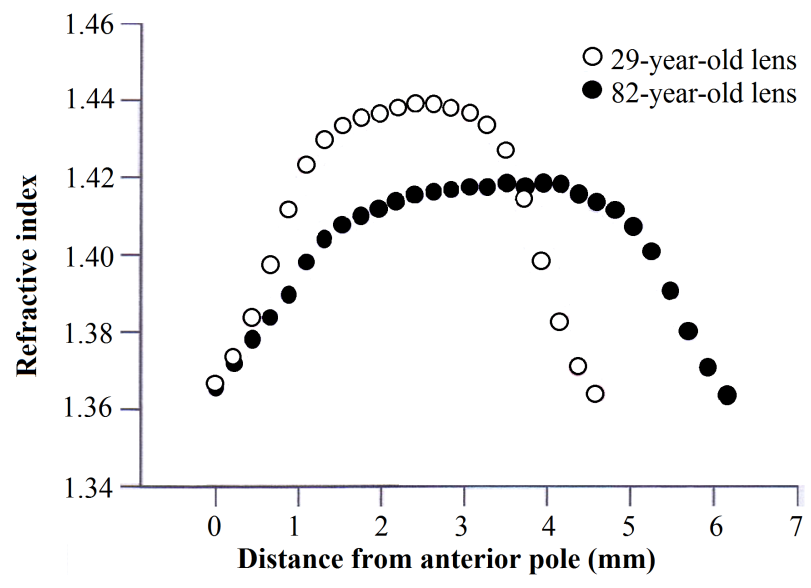

Fig. 3. Lens refractive index decreases with increasing age, Moffat et al. (2002) 17

With the help of numerical analyses - based on finite element method - we will show the connection between the age-related parameters and the amplitude of accommodation. The varied parameters are the geometry, the material properties and the refractive index. These applied data are mostly based on literature values. Finally, the calculated values will be compared to measurement results of Tsorbatzoglou et al. (2007). [21]

\section{Materials and methods}

Numerical simulations are carried out with the ANSYS Mechanical APDL code. Our three-dimensional complex continuum model contains the following anatomical parts of the eye: sclera, cornea, ciliary body, the lens with its three parts (lens nucleus, lens cortex and capsule), aqueous humour, vitreous body, zonular fibres and the supporting fat tissue (see Figure 4). The geometric and material properties are rather age-related. The applied geometric and material properties are based on several works: Abolmaali et al. (2007) [1], Burd et al. (2002) [7], Liu et al. (2006) [16], Krag et al. (1997, 2003) [13, 14], Levin et al. (2011) [15], Power (2001) [18], Strenk et al. (1999) [20] and Fisher $(1969,1971,1977)$ [8-[10].

\subsection{Geometry}

In Figure 5, we can see the basic geometric dimensions of section of the human eyeball. Table 1 and Figure 6 show the various geometric parameters, and Figure 7 shows the applied 

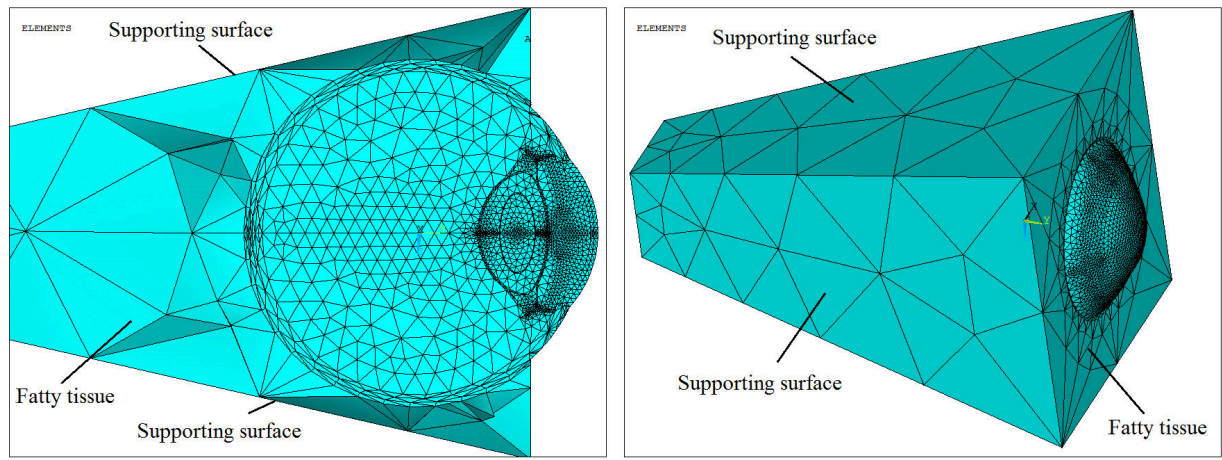

Fig. 4. The modelled parts, fatty tissue, the supports and the section of our FE model

lens cortex geometry based on equation (2), Abolmaali et al. (2007) [1]:

$$
y(x)=\left[b+c\left(\sin ^{-1}\left(\frac{x}{a}\right)\right)^{2}+d\left(\sin ^{-1}\left(\frac{x}{a}\right)\right)^{4}\right] \cos \left(\sin ^{-1}\left(\frac{x}{a}\right)\right),
$$

where $a$ and $b$ were shown in Figure 6, $c$ and $d$ are parameters of curvature, $\left(c_{\text {anterior }}=-0.266892 \mathrm{~mm}, d_{\text {anterior }}=0.1166546 \mathrm{~mm}\right.$, $c_{\text {posterior }}=-0.368996 \mathrm{~mm}, d_{\text {posterior }}=0.000679 \mathrm{~mm}$ ).

The thickness of the lens capsule is changing too with aging, Krag et al. (1997) [13], see Table 2

The ratio between the estimated amount of anterior, central and posterior zonular fibers are 6:1:3, Burd et al. (2002) [7], Liu et al. (2006) [16] so we have used the thicknesses based on Table 3

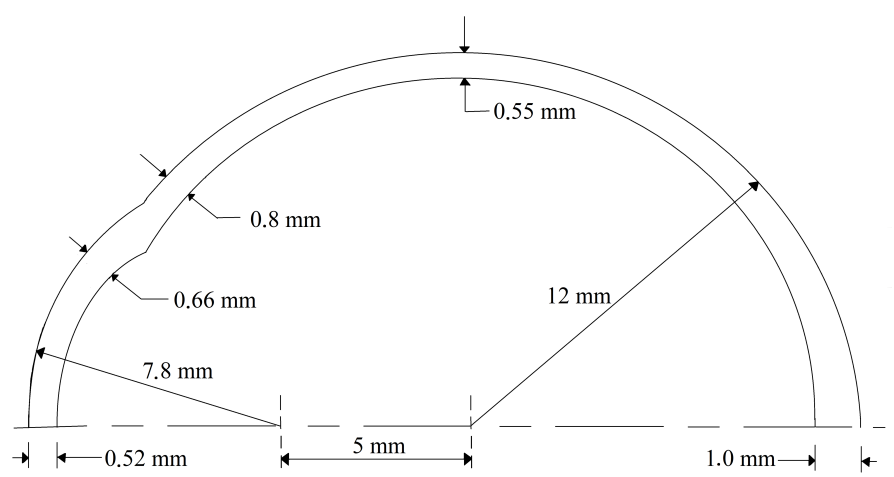

Fig. 5. Geometry of the section

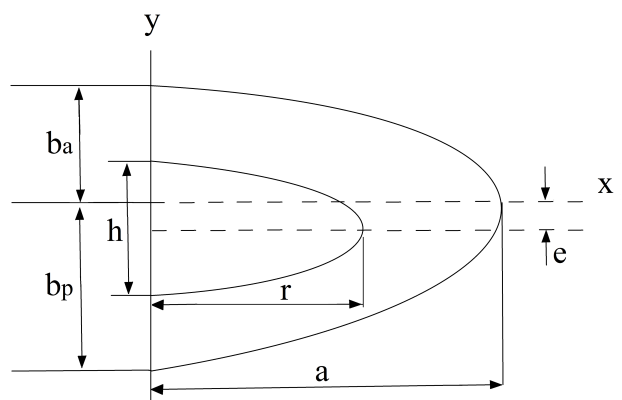

Fig. 6. The geometry of the nucleus and the cortex

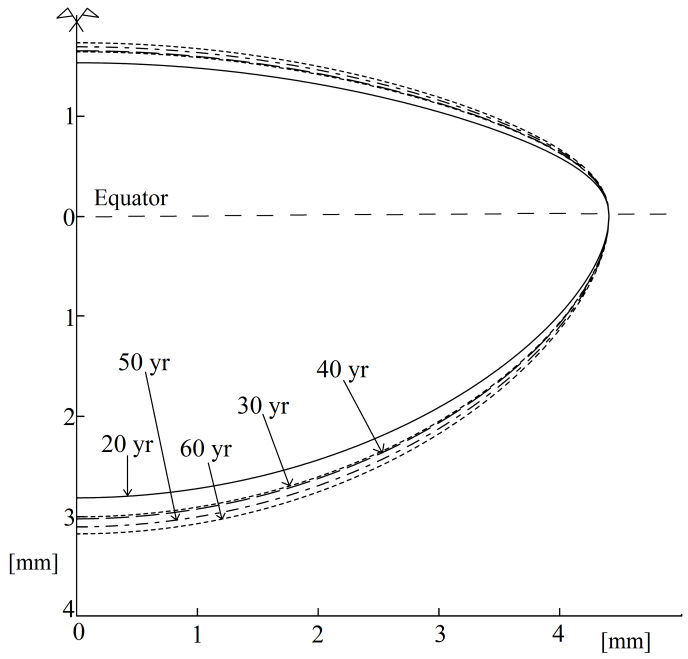

Fig. 7. The applied geometry of the lens cortex in different ages

Tab. 1. The geometry of the lens

\begin{tabular}{ccccc}
\hline Age [yr] & $\begin{array}{c}\text { Lens } \\
\text { equatorial } \\
\text { radius }(a) \\
{[\mathrm{mm}]}\end{array}$ & $\begin{array}{c}\text { Lens } \\
\text { thickness in } \\
\text { accommo- } \\
\text { dated state } \\
\left(b_{a}+b_{p}\right) \\
{[\mathrm{mm}]}\end{array}$ & $\begin{array}{c}\text { Nucleus } \\
\text { radius }(r) \\
{[\mathrm{mm}]}\end{array}$ & $\begin{array}{c}\text { Nucleus } \\
\text { thickness } \\
(h)[\mathrm{mm}]\end{array}$ \\
\hline 20 & 4.40 & $\begin{array}{c}4.35 \\
(1.53+2.82)\end{array}$ & 2.72 & 2.20 \\
\hline 30 & 4.40 & $\begin{array}{c}4.65 \\
(1.64+3.01)\end{array}$ & 2.72 & 2.30 \\
\hline 50 & 4.40 & $\begin{array}{c}4.68 \\
(1.65+3.03)\end{array}$ & 2.72 & 2.40 \\
\hline 60 & 4.40 & $\begin{array}{c}4.80 \\
(1.69+3.11)\end{array}$ & 2.80 & 2.45 \\
\hline
\end{tabular}

Tab. 2. The thickness of lens capsule

\begin{tabular}{ccc}
\hline Krag (2003) & \multicolumn{2}{c}{ Capsule thickness $[\mu \mathrm{m}]$} \\
\hline Age $[\mathrm{yr}]$ & Anterior & Posterior \\
\hline 20 & 18 & 5 \\
\hline 30 & 19 & 6 \\
\hline 40 & 20 & 6 \\
\hline 50 & 22 & 6 \\
\hline 60 & 25 & 6
\end{tabular}


Tab. 3. The properties of zonular fibres

\begin{tabular}{cccc}
\hline $\begin{array}{c}\text { Burd (2002), } \\
\text { Liu (2006) }\end{array}$ & Anterior & Central & Posterior \\
\hline Ratio & 6 & 1 & 3 \\
\hline Thickness & $0.4 \mathrm{~mm}$ & $0.0667 \mathrm{~mm}$ & $0.2 \mathrm{~mm}$ \\
\hline
\end{tabular}

\subsection{Materials}

There are fewer publications about material properties than on geometric parameters because the exact in vivo measurements of these materials are not as easy as measuring the geometry (PCI, MRI, Pentacam, etc.), sometimes even impossible. So we applied linear elastic, isotropic material models, because based on our opinion, it is appropriate for global analyses in this case.

We consider the changing in Young's modulus of the lens cortex, nucleus and capsule. These parameters are shown in Table 4 and 5 and Figure 8 . The data of Figure 8 are based on equation (3) from Fisher (1971) [9], where $E_{N}$ is the Young's modulus of nucleus and $E_{C}$ is the Young's modulus of cortex.

$$
\begin{aligned}
& E_{N}\left(A_{y r}\right)=a_{N}+b_{N} \cdot A_{y r}+c_{N} \cdot A_{y r}^{2}+d_{N} \cdot A_{y r}^{3}[\mathrm{kPa}] \\
& E_{C}\left(A_{y r}\right)=a_{C}+b_{C} \cdot A_{y r}+c_{C} \cdot A_{y r}^{2}[\mathrm{kPa}],
\end{aligned}
$$

where $a_{N}=0.64 ; b_{N}=-3.529 \cdot 10^{-3} ; c N=4.286 \cdot 10^{-4} ; d_{N}=$ $1.518 \cdot 10^{-5} ; a_{C}=0.46 ; b_{C}=1.45 \cdot 10^{-1} ; c_{C}=-1.484 \cdot 10^{-3}$.

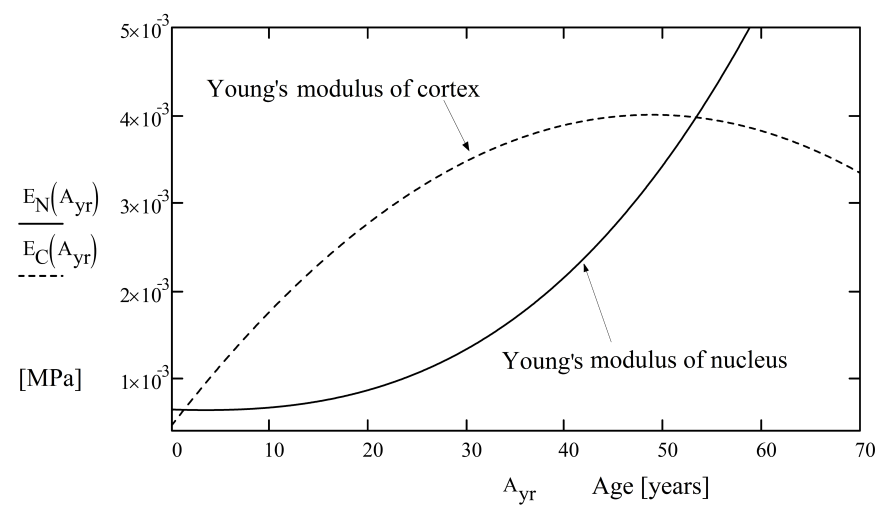

Fig. 8. Young's modulus of cortex and nucleus with increasing age, Fisher (1971)

Table 5 shows that the Young's modulus of the cortex, nucleus and capsule are getting higher with aging, so the lens and its components become more rigid.

We note that the range of initial Young's modulus of cornea and sclera is wide, based on the literature (see Fig 9). In section 3 , we show that the tendency of the results is the same when we applied lower elastic modulus for the sclera and cornea (seven times lower than the Young's modulus in Table 4, based on the work by Śródka et al. (2011) [19]).

\subsection{Calculations}

We applied shell elements (SHELL281) for zonular fibres and lens capsule because the thicknesses of these parts are negligible compared to the other considered parts. Volume elements (SOLID186) were used for the rest of the parts (see Figure 4).

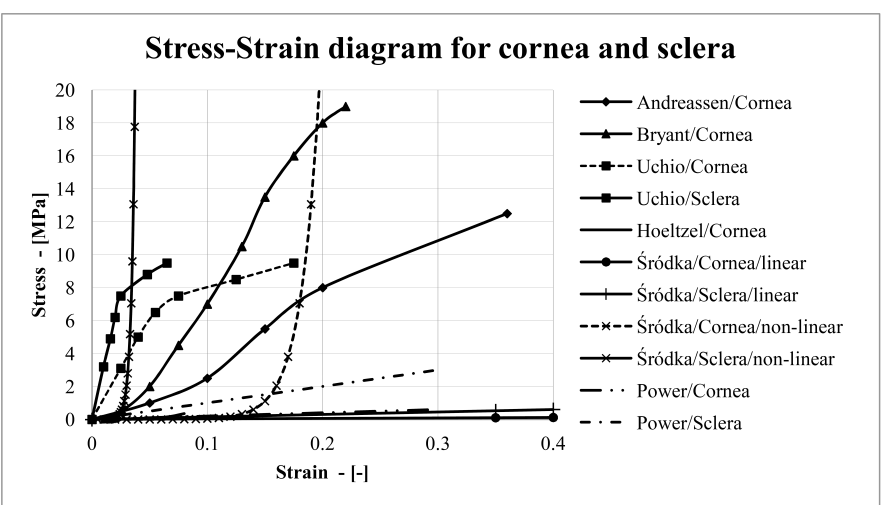

Fig. 9. Range of material properties of cornea and sclera

Tab. 4. Mechanical properties of the modelled parts

\begin{tabular}{cccc}
\hline Power (2001) & $\begin{array}{c}\text { Young's } \\
\text { modulus [MPa] }\end{array}$ & $\begin{array}{c}\text { Poisson's ratio } \\
{[-]}\end{array}$ & Density $\left[\mathrm{kg} / \mathrm{m}^{3}\right]$ \\
\hline $\begin{array}{c}\text { Aqueous } \\
\text { Humour }\end{array}$ & 0.037 & 0.49 & 1006 \\
\hline Ciliary Muscle & 11 & 0.4 & 1600 \\
\hline Cornea & 2 & 0.42 & 1400 \\
\hline Fat & 0.047 & 0.49 & 999 \\
\hline Sclera & 10 & 0.4 & 1400 \\
\hline Vitreous Body & 0.042 & 0.49 & 1006 \\
\hline Zonular Fibres & 1.5 & 0.4 & 1000 \\
\hline
\end{tabular}

We applied an axisymmetric tensile force on zonular fibres through the ciliary muscles (see Figure 10) Bocskai and Bojtár (2012) [4], so we stretched the lens from the accommodated state to the unaccommodated state (see Figure 11). As a boundary condition, we set zero displacements on those nodes, which are lying on the supporting surface at the border of the fatty tissue (see Figure 4).

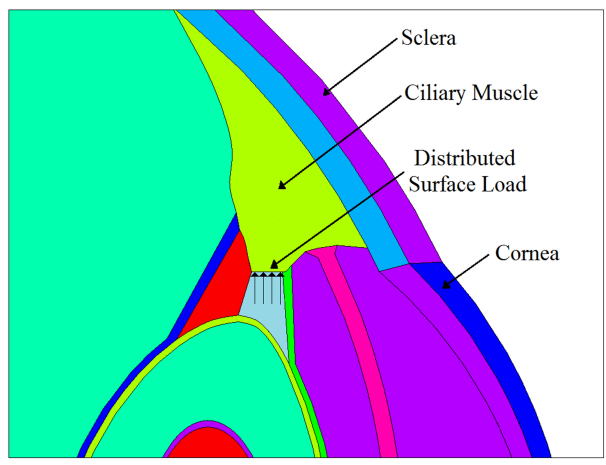

Fig. 10. The applied distributed surface load

With this complex numerical model we can analyse different problems, for instance, the accommodation of the human eye or effects of the refractive eye-surgeries and traumas, where the corneal thickness reduces as consequence of refractive surgery, therefore the intraocular pressure induces changes in the corneal curvature, or it could damage the cornea, and so on.

To analyse the accommodation process we need to have the diopter of the lens in different ages in different states (accommodated, unaccommodated). For the calculation of central optical 
Tab. 5. The Young's modulus of the lens components

\begin{tabular}{cccc}
\hline Age [yr] & $\begin{array}{c}\text { Young's modulus of } \\
\text { nucleus [MPa] } v=0.49 \\
(\text { Fisher, 1971) }\end{array}$ & $\begin{array}{c}\text { Young's modulus of } \\
\text { cortex [MPa] } v=0.49 \\
(\text { Fisher, 1971) }\end{array}$ & $\begin{array}{c}\text { Young's modulus of } \\
\text { capsule [MPa] } v=0.47 \\
\text { (Krag, 1997) }\end{array}$ \\
\hline 20 & 0.000862 & 0.002766 & 1.00 \\
\hline 30 & 0.001329 & 0.003474 & 1.30 \\
\hline 40 & 0.002156 & 0.003886 & 1.45 \\
\hline 50 & 0.003433 & 0.004000 & 1.45 \\
\hline 60 & 0.005250 & 0.003818 & 1.45 \\
\hline
\end{tabular}
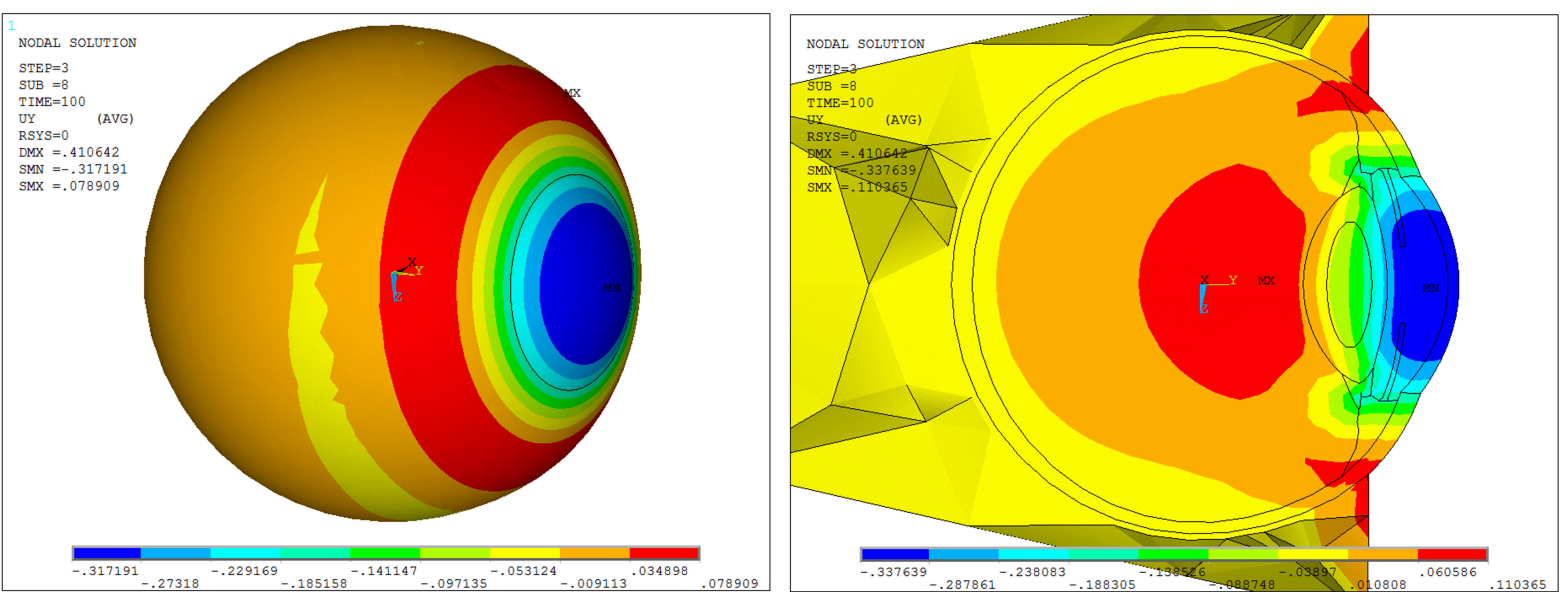

Fig. 11. The displacements in lens axis direction, only the eyeball (left) and section view (right)

power (COP), we used a polynomial regression on the nodal coordinates in the symmetry plane of the lens in deformed and undeformed states. With this polynomial function we can define the radii of curvature in the optical axis. The curvature has been calculated based on the following well-known equation:

$$
\kappa=\frac{\frac{d^{2} f(x)}{d x^{2}}}{\left[1+\left(\frac{d f(x)}{d x}\right)^{2}\right]^{\frac{3}{2}}} .
$$

The reciprocal of the curvature is the radius of curvature. Based on equation (1) and equation (4) the amplitude of accommodation is definable.

\section{Results}

We analyzed the amplitude of accommodation with aging. The central optical power (COP) has been calculated in four different cases. In all four cases and in all ages the intensity of the stretching force was the same, Fisher (1977) [10] but the material properties of the lens nucleus, cortex and capsule, and the thickness of the capsule were diverse in these periods. In the first case we assumed that the lens geometry and the refractive index of the lens are constant in all ages, so only the material parameters and the thickness of the lens capsule were variable. In the second case the geometry was the same in every age, but we take into consideration that the refractive index and material properties are changing. In the third case the geometry of the lens cortex and nucleus were age-related, but the refractive index remained constant, and in the fourth case both the lens geometry and the refractive index of the lens were age-related.

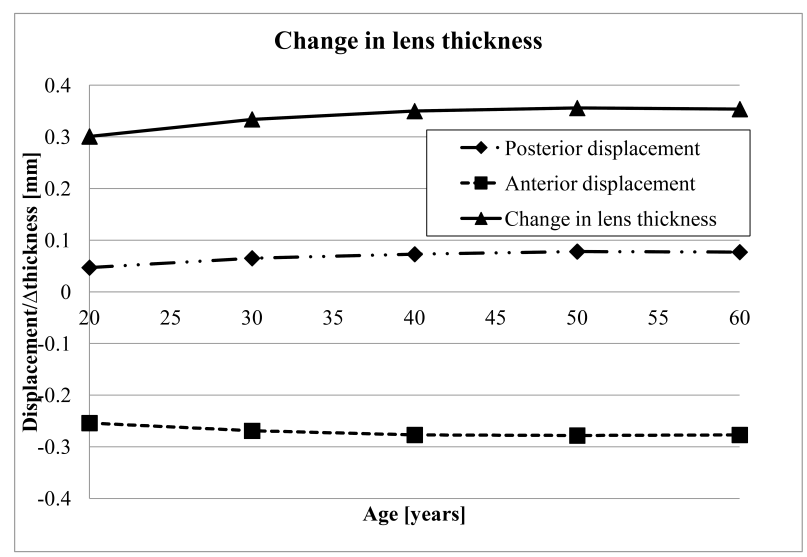

Fig. 12. Change in lens thickness, case 1 and case 2

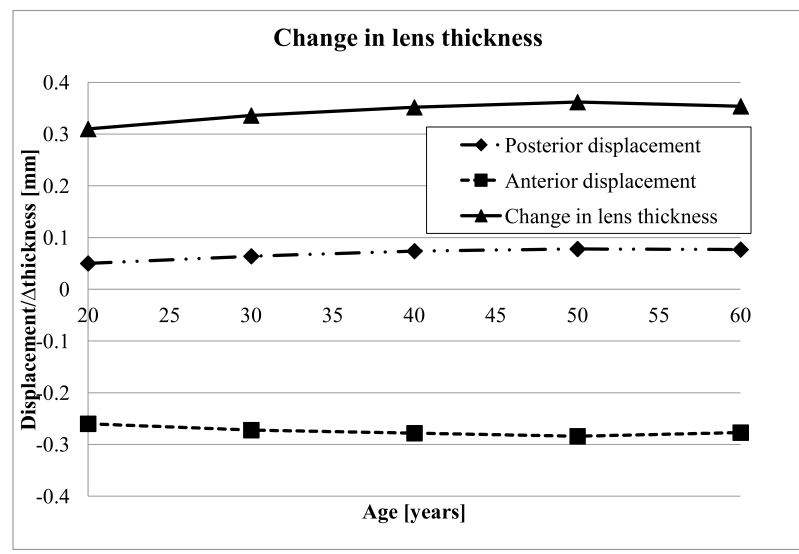

Fig. 13. Change in lens thickness, case 3 and case 4 
In Figure 12 and 13 , we can see the displacements of the anterior and the posterior surface of capsule in lens axis. Figure 12 and 13 also shows the changes in lens thickness with increasing age, (Figure 12 belongs to case 1 and 2; and Figure 13 belongs to case 3 and 4). Because the crystalline lens becomes less flexible (more rigid), the changes in lens thickness are increasing due to the complex model, boundary conditions and loads. We calculated the central optical power $(C O P)$ of the lens with the initial geometry and with the deformed shape (in accommodated and unaccommodated states). In Figure 14, we can see the alteration of diopter in accommodated and unaccommodated situations in all four analysed cases.

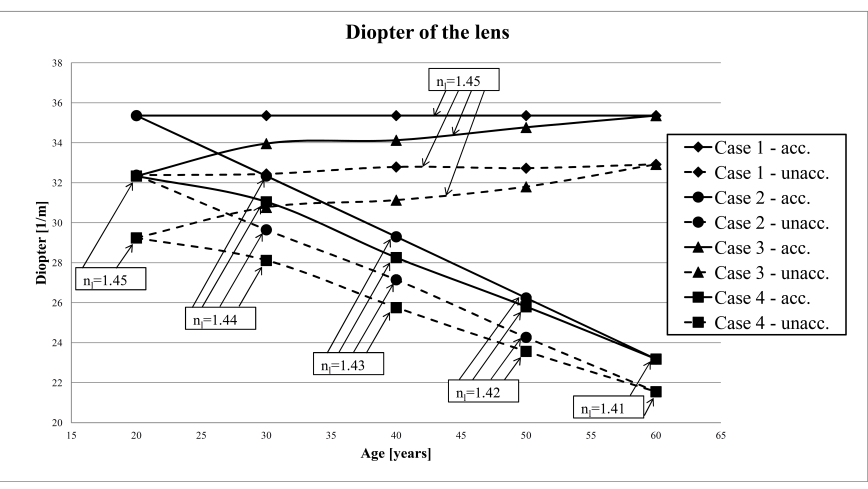

Fig. 14. The diopter of the lens in different cases

In case 1 , because the initial geometry (accommodated state) was the same in each analysed age, and the refractive index was constant, we can see different optical power only in unaccommodated states (as shown in Figure 14). In case 2 we consider that the refractive index decreases with aging, but the geometry was the same as in case 1 , so we can see that the diopter of the lens in accommodated and unaccommodated states are smaller, than in case 1 .

In case 3, we considered that the lens is getting thicker with aging Strenk et al. (1999) [20], Levin et al. (2011) [15], and its curvature is getting larger. As we can see in Figure 14, the diopter of the lens increases during aging in accommodated and unaccommodated states too (case 3). This is what we call "lens paradox", Moffat et al. (2002) [17].

To resolve this paradox we analysed case 4 , where we calculated the optical power of the lens based on the fact that the lens thickens, and the refractive index decreases with aging. We can also see these results in Figure 14. In case 4 the initial values of diopter are the same as in case 3 , and the final values are the same as in case 2 as expected.

It should be noted, that in Figure 11, we can see that during the accommodation, the corneal curvature is changing too. $A k$ ihiro et al. (2003) [2] corroborate this effect based on clinical measurements.

\section{Discussion and Conclusions}

With the results of the previous chapter, we can calculate the amplitude of accommodation if we subtract the diopter of un- accommodated state from the diopter of accommodated state. Based on the finite element and optical calculations, our numerical results in all examined cases confirm that the amplitude of accommodation $(\triangle C O P)$ reduces with aging (see Figure 15 ).

Considering that the refractive index of the crystalline lens decreases with increasing age Moffat et al. (2002) [17], Borja et al. (2008) [5], and the thickness of the lens is increasing Strenk et al. (1999) [20], the most accurate calculation is case 4.

We can say that the accommodation width (amplitude of accommodation) is getting worse if we consider the decreasing of the refractive index of the lens (case 2 and case 4). The decreasing tendency of the amplitude of accommodation is based on numerical and optical calculations, and is shown in Figure 15. We demonstrated that beside the age-related material and geometric properties, the effect of the refractive index of the lens is also important (Figure 15).

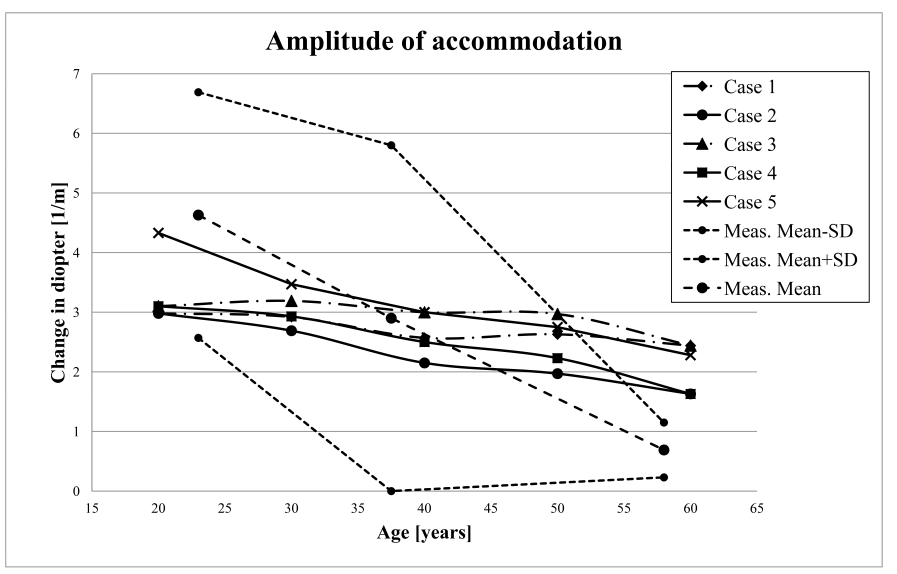

Fig. 15. The amplitude of accommodation in the different cases

Figure 15 (case 5) also shown the results that we get if we use reduced elastic modulus for sclera and cornea, what we mentioned in section 2.2. Besides, in case 5, we consider the decreasing of refractive index and the age-related material and geometric parameters.

If we compare our numerical results with values measured by Tsorbatzoglou et al. (2007) [21] based on defocusing technique, we obtain the following diagram (see also Figure 15). Subjects were divided into 3 age groups: younger than 30 years (Group 1), between 31 years and 44 years (Group 2), and older than 45 years (Group 3). The youngest subject was 16 and the oldest was 71 years old. We can find good agreement in the tendency of the amplitude of the accommodation between our numerical calculations and the measured results.

Based on this information, we established that at the analyses of accommodation not only the age-related material and geometric properties, but the age-related optical parameters are important with the same weight, and so we can understand the "lens paradox" easily. We also note that we considered in the calculation of the central optical power only the effects of the lens, the vitreous body and the aqueous humour, and the refractive index of the lens was assumed to be constant along the optical axis. 


\section{Acknowledgements}

The authors would like to express their gratitude to Dr. Andrea Kerek for her interest, support, and valuable guidance.

The work reported in the paper has been developed in the framework of the „Talent care and cultivation in the scientific workshops of BME“ project. This project is supported by the grant TÁMOP-4.2.2.B-10/1-2010-0009.

\section{References}

1 Abolmaali A, Schachar RA, Le T, Sensitivity study of the human crystalline lens accommodation, Computer Methods and Programs in Biomedicine, 85, (2007), 77-90, DOI 10.1016/j.cmpb.2006.08.005.

2 Akihiro Y, Tatsuo Y, Kishiko $\mathbf{O}$, Changes in corneal curvature in accommodation, Journal of Cataract Refractive Surgery, 29, (2003), 1297-1301, DOI 10.1016/S0886-3350(03)00118-4.

3 Andreassen TT, Simonsen AH, Oxlund H, Biomechanical properties of keratoconus and normal corneas, Experimental Eye Research, 31, (1980), 435-441, DOI 10.1016/S0014-4835(80)80027-3.

4 Bocskai Z, Bojtár I, Biomechanical analyses of the human eye, In: Kiss R (ed.), Biomechanikai modellezés: Monográfia, TERC; Budapest, 2012, pp. 187-202. in Hungarian.

5 Borja D, Manns F, Ho A, Ziebarth N, Rosen AM, Jain R, Amelinckx A, Arrieta E, Augusteyn RC, Parel JM, Optical power of the isolated human crystalline lens, Investigative Ophthalmology and Visual Science, 49(6), (2008), 2541-2548, DOI 10.1167/iovs.07-1385.

6 Bryant MR, Szerenyi K, Schmotzer H, McDonnell PJ, Corneal tensile strength in fully healed radial keratotomy wounds, Investigative Ophthalmology and Visual Science, 35(7), (1994), 3022-3031.

7 Burd HJ, Judge SJ, Flavel NJ, Numerical modelling of the accommodating lens, Vision Research, 42, (2002), 2235-2251.

8 Fisher RF, Elastic constants of the human lens capsule, Journal of Physiology, 201, (1969), 1-19.

9 Fisher RF, The elastic constants of the human lens, Journal of Physiology, 212, (1971), 147-180.

10 Fisher RF, The force of contraction of the human ciliary muscle during accommodation, Journal of Physiology, 270, (1977), 51-74.

11 Hartridge $\mathbf{H}$, Helmholtz's theory of accommodation, British Journal of Ophthalmology, 9, (1925), 521-523, DOI 10.1136/bjo.9.10.521.

12 Hoeltzel DA, Altman P, Buzard KA, Choe K, Strip extensiometry for comparison of the mechanical response of bovine, rabbit and human corneas, Journal of Biomechanical Engineering, 114, (1992), 202-215, DOI 10.1115/1.2891373.

13 Krag S, Andreassen TT, Olsen T, Biomechanical characteristic of human anterior lens capsule in relation to age, Investigative Opthalmology and $\mathrm{Vi}$ sual Science, 38, (1997), 357-363.

14 Krag S, Andreassen TT, Mechanical properties of the human posterior lens capsule, Investigative Ophtalmology and Visual Science, 44(2), (2003), 691-696, DOI 10.1167/iovs.02-0096.

15 Adler's physiology of the eye, 11th, Elsevier Saunders, 2011.

16 Liu Z, Wang B, Xu XZ, Wang C, A study for accommodating the human crystalline lens by finite element simulation, Computerized Medical Imaging and Graphics, 30, (2006), 371-376, DOI 10.1016/j.compmedimag.2006.09.008.

17 Moffat BA, Atchison DA, Pope JM, Explanation of the lens paradox, Optometry and Vision Science, 79, (2002), 148-150.

18 Power ED, A nonlinear finite element model of the human eye to investigate ocular injuries from night vision goggles, Master thesis, Virginia Polytechnic Institute; Blacksburg, Virginia, 2001.

19 Śródka W, Evaluating the material parameters of the human cornea in a numerical model, Acta of Bioengineering and Biomechanics, 13(3), (2011), 77-85.

20 Strenk SA, Semmlow JL, Strenk LM, Munoz P, Gronlund-Jacob J, DeMarco JK, Age-related changes in human ciliary muscle and lens: A magnetic resonance imaging study, Investigative Ophthalmology and Visual Science, 40(6), (1999), 1162-1169.

21 Tsorbatzoglou A, Németh G, Széll N, Biró Z, Berta A, Anterior segment changes with age and during accommodation measured with partial coherence interferometry, Journal of Cataract and Refractive Surgery, 33, (2007), 1597-1601, DOI 10.1016/j.jcrs.2007.05.021.

22 Uchio E, Ohno S, Kudoh J, Aoki K, Kisielewicz LT, Simulation model of eyeball based on finite element analysis on a supercomputer, British Journal of Ophthalmology, 83, (1999), 1106-1111, DOI 10.1136/bjo.83.10.1106. 